\title{
Na interface do embasamento, solos e cobertura: a suscetibilidade à desertificação da Sub-bacia Hidrográfica do Rio Figueiredo, Ceará
}

\author{
At the interface of basement, soils and cover: susceptibility to the desertification of the \\ Figueiredo River Hydrographic Sub-basin, Ceará
}

Sérgio Domiciano Gomes de Souza

Universidade do Estado do Rio Grande do Norte, Brasil sergio_gsousa@hotmail.com

Anny Catarina Nobre de Souza Graduanda em Geografia - Universidade do Estado do Rio Grande do Norte, Brasil

anny-catarina13@,hotmail.com

Maria Losângela Martins de Sousa Professora Adjunta do Departamento de Geografia da Universidade do Estado do Rio Grande do Norte, Brasil mariasousa@uern.br

\begin{abstract}
Resumo
A desertificação é um problema ambiental grave que afeta as zonas áridas, semiáridas e subúmidas secas do planeta Terra. Por essa razão, o trabalho visa analisar como a geologia, os solos e a vegetação indicam a suscetibilidade à desertificação da Sub-bacia Hidrográfica do Rio Figueiredo (SBHRF). Assim, buscou-se conhecer as condições geoambientais da área a partir dos sistemas ambientais; verificar a permoporosidade das rochas presentes na sub-bacia; identificar as principais associações de solos; observar a vulnerabilidade dos sistemas ambientais à erosão, bem como o uso e cobertura do solo. Para tanto, foi utilizado o marco metodológico dos indicadores biofísicos de Abraham e Beekmam (2006) associados aos geobiofísicos de Oliveira (2011) para aplicação na área em estudo. Desse modo, a área se apresenta com suscetibilidade que varia de moderada a alta à desertificação, pela baixa permoporosidade das rochas cristalinas que embasam a área, pela vulnerabilidade à erosão que varia de estabilidade mediana com tendência a vulnerável, bem como o estado atual da cobertura vegetal que se apresenta fortemente degradada.
\end{abstract}

Palavras-chave: Semiárido; Indicadores Geobiofísicos; Desertificação; Geossistemas; Litologia; Erosão; Vegetação.

\begin{abstract}
Desertification is a serious environmental problem that affects the arid, semi-arid and sub-humid dry areas of planet Earth. For this reason, the work aims to analyze how geology, soils and vegetation indicate susceptibility to the desertification of the Rio Figueiredo Hydrographic Sub-basin (SBHRF). Thus, it was sought to know the geo-environmental conditions of the area from the environmental systems; check the permoporosity of the rocks present in the sub-basin; identify the main soil associations; observe the vulnerability of environmental systems to erosion, as well as land use and cover. For this purpose, the methodological framework of the biophysical indicators of Abraham and Beekmam (2006) associated with the geobiophysicists of Oliveira (2011) was used for application in the study area. Thus, the area presents itself with susceptibility that varies from moderate to high to desertification, due to the low permoporosity of the crystalline rocks that support the area, the
\end{abstract}


vulnerability to erosion that varies from medium stability with a tendency to vulnerable, as well as the current state of coverage plant that is strongly degraded.

Keywords: Semiarid; Geobiophysical Indicators; Desertification; Geosystems; Lithology; Erosion; Vegetation.

\section{INTRODUÇÃO}

A desertificação é um processo de degradação ambiental em estado avançado. Apresenta gravidade por ser oriunda das condições naturais agravadas pelas ações humanas, que levam à exaustão das terras e seus recursos. Sendo possível de ocorrer nas áreas específicas do planeta Terra: áridas, semiáridas e subúmidas secas (NASCIMENTO, 2013).

Contudo, é primordial distinguir desertificação de deserto, pois, embora haja semelhança semântica, são diferentes. O deserto é uma região árida, caracterizada por uma discrepância entre a precipitação e evapotranspiração potencial, bem como o desenvolvimento carente da biosfera. Já a desertificação, configura-se como um processo que leva a escassez dos organismos vivos e o declínio da atividade biológica (CONTI, 2008, p. 44). Portanto a diferença são as causas. Enquanto o deserto é uma região natural oriunda da desertização, a desertificação é agravada pela ação humana, e não leva a constituição de um deserto, naturalmente (NASCIMENTO, 2013, p. 18).

No contexto nacional, o semiárido brasileiro com $15,72 \%$ do território é a área com maior suscetibilidade à desertificação, onde vivem 31,6 milhões de pessoas, vis à vis as agruras físicas, naturais e econômicas em relação ao quadro paisagístico das outras regiões (PAN-BRASIL, 2004, p. 23). Tendo o estado do Ceará como um dos mais vulneráveis, inserido quase que totalmente nas Áreas Susceptíveis à Desertificação (ASDs), com três núcleos de desertificação: Irauçuba, Inhamuns e Jaguaribe (PAE/CE, 2010, p. 20).

No bojo dessa discussão, o meio científico tem se esforçado para esclarecer o fenômeno, produzindo metodologias para a identificação da suscetibilidade à desertificação, como é o caso de Abraham e Beekman (2006) que sistematizaram os indicadores biofísicos, socioeconômicos e institucionais para a América do Sul, replicados por Oliveira (2011), Sousa (2016) e Souza, Souza e Sousa (2020) em bacias hidrográficas de regiões semiáridas da África e do Brasil.

Nesse sentido, emerge a necessidade de aportes teórico-metodológicos que abarquem a interdisciplinaridade de conhecimentos na compreensão da desertificação. Onde a teoria Geossistêmica se apresenta como fundamental já que é "um sistema controlado no qual o homem introduz modificações na forma quando age sobre sua estrutura e promove nela transformações que se dão em cascata" (VEADO, 1995, p. 33). Sendo a bacia hidrográfica o recorte territorial representativo dessas relações sistêmicas, uma vez que se constitui de divisores de água com elevações, um rio principal e seus afluentes, ocasionando o transporte de água e sedimentos. Por essa 
razão, é que processos de interferência humana ou distúrbios naturais ocorrentes repercutem em todo o ambiente. Portanto fundamental para a recuperação de áreas degradadas (ARAUJO, 2010, p. 59).

Nesse ínterim, o presente trabalho tem o objetivo de analisar como a geologia, os solos e a vegetação indicam a suscetibilidade à desertificação da Sub-bacia Hidrográfica do Rio Figueiredo (SBHRF). Sendo que de maneira específica buscou-se conhecer as condições geoambientais da área a partir dos sistemas ambientais; verificar a permoporosidade das rochas presentes na sub-bacia; identificar as principais associações de solos; observar a vulnerabilidade dos sistemas ambientais à erosão, bem como o uso e cobertura do solo.

O trabalho é importante para o meio científico e social, pois ao adotar a desertificação, investigada in lócus, não se constatou uma adversidade ambiental apenas, mas um fato, que no Brasil, é peculiar ao semiárido, condicionado pelas circunstâncias naturais e humanas do passado e do presente, que podem se reverter em prejuízos ambientais e sociais no futuro. É pertinente nos estudos geográficos, uma vez que esta Ciência abarca as relações da sociedade com a natureza no espaço geográfico. Portanto, a desertificação como degradação, se configura como resultado dessa interrelação.

Além disso, considera a delimitação territorial da bacia hidrográfica, por ser nela onde se observa mais holisticamente o arranjo da configuração dos elementos naturais e as ações sociais atuantes nessa célula de estudo. Possibilitando assim, uma análise integrada da paisagem que venha a servir, ainda, ao planejamento ambiental.

Assim, o presente estudo encontra-se organizado em três seções. Na primeira apresenta-se os procedimentos metodológicos da pesquisa. Na segunda, caracteriza a SBHRF em torno de seus atributos geoambientais e localização. Por último, se argui comprovando a hipótese, sobre a suscetibilidade à desertificação da SBHRF com base nos indicadores aplicados.

\section{METODOLOGIA}

A pesquisa configura-se como sendo, em relação aos objetivos, exploratória, por realizar um levantamento bibliográfico e geocartográfico na busca de informação do assunto pesquisado; explicativa por buscar, por meio de uma análise aprofundada, a explicação e as variáveis que incidem na ocorrência de um fenômeno; e de campo uma vez que se utiliza da observação dos fatos para correlacioná-los e procurar respostas para os acontecimentos (FREITAS; PRODANOV, 2013, p. 49).

Por assim tratar, adotamos o método Geossistema, com base em Sotchava (1977) e Bertrand (2004), na busca de analisar a paisagem em sua totalidade congregando os aspectos do potencial ecológico, da exploração biológica e da ação antrópica no entendimento da configuração geoambiental para a discussão da suscetibilidade à desertificação na área. 
Assim, realizou-se os procedimentos em etapas de gabinete e campo. No que concerne ao gabinete, foi feito levantamentos bibliográfico, geocartográfico e de imagens de satélite seguida das devidas leituras e interpretações, bem como da utilização das técnicas de geoprocessamento e sensoriamento remoto para a produção de mapas temáticos, além da tabulação de dados, análise e discussão dos resultados subsidiadas pela segunda etapa, os trabalhos de campo, com o reconhecimento da verdade terrestre.

No tocante ao levantamento bibliográfico, este se deu pelos eixos temáticos: desertificação, indicadores geobiofísicos, geossistemas e, contextualização ambiental e social da área em estudo. No levantamento geocartográfico, foi realizada a interpretação de mapas exploratórios a partir das cartas topográficas do Projeto RADAM/BRASIL (1981) das Folhas Jaguaribe/Natal SB.24/25 e do Mapa Geológico do Ceará (CPRM, 2020). Conjunto, o levantamento de dados a respeito das características geoambientais e socioeconômicas nos sites do Instituto Brasileiro de Geografia e Estatística (IBGE) e da Fundação Cearense de Meteorologia e Recursos Hídricos (FUNCEME), desconsiderando o município de São João do Jaguaribe uma vez que este possui apenas $2 \%$ de seu território inserido na sub-bacia, e esses dados fazem referência aos territórios municipais em sua totalidade. Bem como foram elaborados produtos cartográficos da área de estudo, no que concerne suas principais associações de solo, geologia, cobertura do solo e vulnerabilidade à erosão.

De forma complementar, foram realizados trabalhos de campo para evidenciar a verdade terrestre relativo às características do solo, vegetação e usos e ocupação ao longo da sub-bacia em estudo.

Para os indicadores geobiofísicos de desertificação, foram consideradas as abordagens de Abraham e Beeckman (2006) que tratam dos indicadores biofísicos, e Oliveira (2011) e Sousa (2016) com os geobiofísicos. Estes foram adaptados e organizados em valores que indicam o estado de conservação do ambiente e de degradação, onde os maiores valores apontam para uma potencial conservação e os menores para o maior estado de degradação, em um escalonamento de 1 a 5 , conforme a tabela 1 .

Para o mapa de solos usou-se a base cartográfica da Companhia de Gestão dos Recursos Hídricos (2003), as classes de solos do RADAM-BRASIL (1981) com atualização pela EMBRAPA (SANTOS et. al. 2018). Já para o de geologia utilizou-se a base da CPRM (2020), com as litologias da área.

Para a elaboração do mapa de uso e ocupação do solo foram utilizadas e interpretadas imagens do satélite CEBERS 4A do ano de 2020 com 8 metros de resolução espacial, para as quais foram fusionadas as bandas 7, 6 e 5 que revelam as cores verdadeiras da área, a partir de classificação supervisionada no software "Qgis 2.18 - Las Palmas". Adotou-se as nomenclaturas das classes de uso e ocupação do IBGE (2013). 
Tabela 1: Matriz dos Indicadores Geobiofísicos de Desertificação.

\begin{tabular}{|c|c|c|}
\hline \multicolumn{3}{|c|}{ INDICADORES GEOBIOFISICOS DE DESERTIFICAÇĀO } \\
\hline GEOLOGIA (Litotipo/permeabilidade) & V. I. & $\begin{array}{l}\text { JUSTIFICATIVA } \\
\end{array}$ \\
\hline Sedimentos não coesos (arenoso) & 5 & \\
\hline Sedimentos não coesos (areno-argiloso) & 4 & A permoporosidade da rocha, em virtude da sua \\
\hline Rochas Sedimentares (Arenitos conglomerados) & 3 & composição litológica, determina a capacidade de \\
\hline $\begin{array}{l}\text { Rochas Metamórficas (Metamorfismo baixo a } \\
\text { médio }\end{array}$ & 2 & infiltração e armazenamento de água. \\
\hline $\begin{array}{c}\text { Rochas Igneas, Granitos e Granitos } \\
\text { Migmatizados }\end{array}$ & 1 & \\
\hline SOLOS (Vulnerabilidade a perda de solo) & V. I. & JUSTIFICATIVA \\
\hline Estável & 5 & \\
\hline Moderadamente estável & 4 & O grau de erosão indica a degradação ambiental, \\
\hline Medianamente estável/vulnerável & 3 & por limitacões e ecodinâmica do ambiente. \\
\hline Moderadamente vulnerável & 2 & \\
\hline Vulnerável & 1 & \\
\hline VEGETAÇÃO (Porcentagem da cobertura) & V.I & JUSTIFICATIVA \\
\hline Alta & 5 & \\
\hline Médio-alta & 4 & A cobertura vegetal influência em toda a dinâmica \\
\hline Média & 3 & sendo fator determinante na conservacão do solo e \\
\hline Médio-baixa & 2 & na da erosão \\
\hline Baixa & 1 & \\
\hline
\end{tabular}

Fonte: Elaborado pelo autor, adaptado de Oliveira (2011) e Sousa (2016). V. I.: Valor do Indicador.

Para o indicador de solo, foi incorporado a metodologia de Crepani (2001) da qual se definiu as classes de vulnerabilidade a perda de solo dos sistemas ambientais. Considerando todos os elementos geoambientais e variáveis seguidos das respectivas técnicas procedimentais: denudação das rochas para geologia; dissecação do relevo, amplitude altimétrica e declividade para geomorfologia com base no RADAM/BRASIL (1981); maturidade dos solos para pedologia; densidade da cobertura vegetal para vegetação pelas bases supracitadas; e intensidade pluviométrica para o clima por meio de um cálculo que considera a soma de precipitações dividida pela quantidade de meses em que choveu no ano de 2019, com base na FUNCEME (2019).

Tais dados foram sistematizados no Excel (2013) atribuindo-se valores a cada variável em função do seu grau de vulnerabilidade à erosão, conforme a metodologia adotada, os quais representados por cores que revelam a intensidade de tal vulnerabilidade foram trabalhos no software Qgis para demonstração da vulnerabilidade dos sistemas ambientais da sub-bacia.

Desse modo, considerando os valores da tabela 1, chega-se a média aritmética dos três indicadores, a partir dos quais se estabelece os índices de suscetibilidade à desertificação conforme os índices da tabela 2.

Tabela 2: Índices Geobiofísicos de Desertificação.

\begin{tabular}{cc}
\hline ÍNDICE GEOBIOFÍSICO DE DESERTIFICAÇÃO & INTERVALOS \\
\hline Muito baixo & $>3,36$ \\
Baixo & $3,20-2,36$ \\
Moderado & $2,80-3,19$ \\
Alto & $2,64-2,79$ \\
\hline
\end{tabular}

Fonte: Elaborado pelos autores, adaptado de Oliveira (2011). 


\section{LOCALIZAÇÃO E CARACTERIZAÇÃO DA ÁREA DE ESTUDO}

A sub-bacia hidrográfica do Rio Figueiredo está localizada no leste do estado do Ceará, divisa com o Rio Grande do Norte (Figura 1). Faz parte da bacia hidrográfica do Médio Jaguaribe e está compartimentada em seis unidades geoambientais: a Planície Fluvial e as áreas de inundação sazonal, Sertões de Alto Santo, Sertões de Iracema/Potiretama, Sertões de Pereiro/Ereré, Maciço Residual do Pereiro, Superfície de exumação da Formação Açu e, as Cristas Residuais dispostas nos sertões. Esses domínios abarcam 100\% do município de Ereré, 98\% de Potiretama, 80\% de Iracema, $54 \%$ de Pereiro, $44 \%$ de Alto Santo e 2\% de São João do Jaguaribe (SOUSA, 2012).

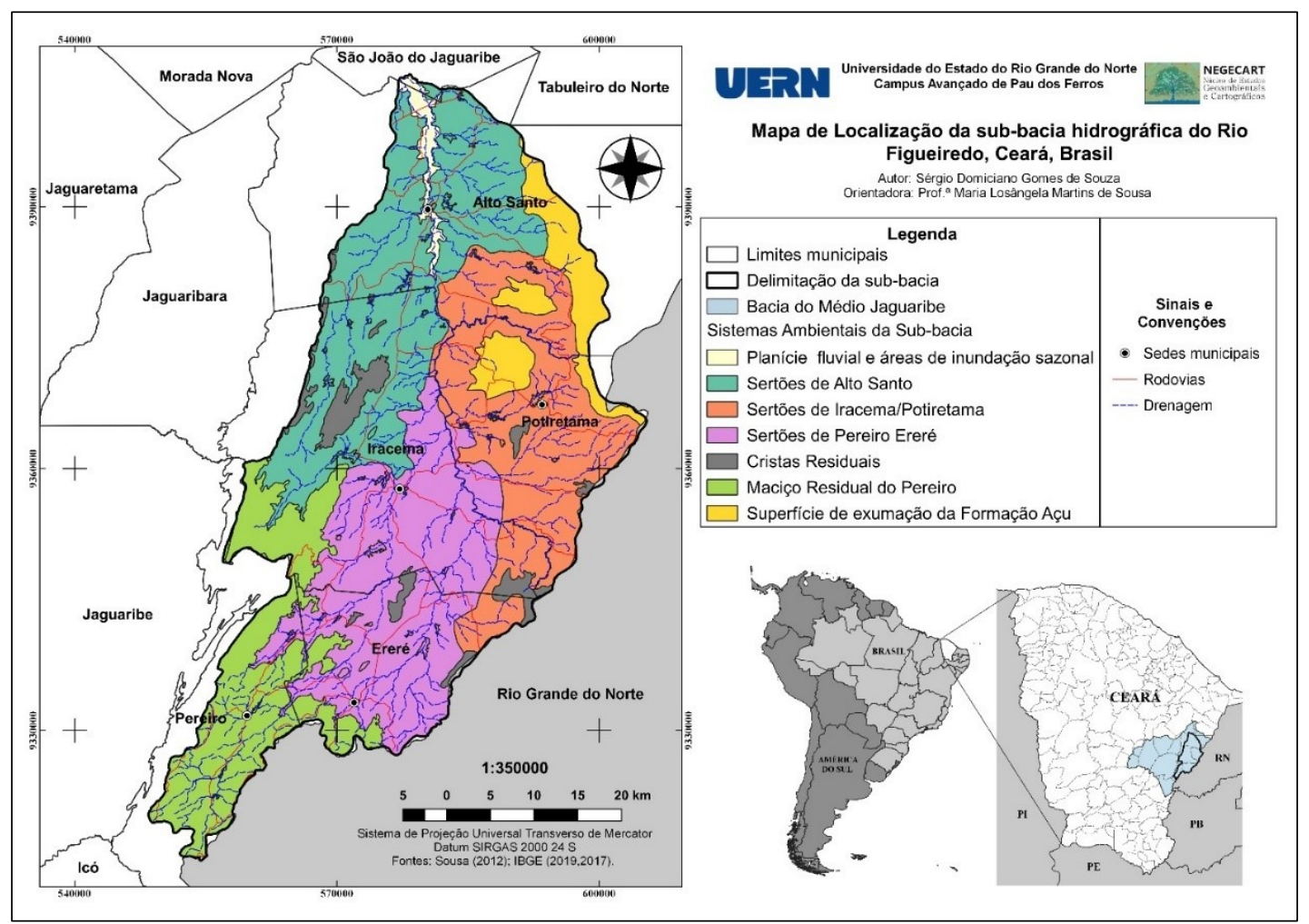

Figura 1 - Mapa de localização dos sistemas ambientais da SBHRF.

Fonte: Elaboração dos autores (2020).

A população da sub-bacia está em torno dos 58 mil habitantes, considerando a população total dos municípios. Esse dado revela uma baixa densidade demográfica da ordem de $25,3 \mathrm{hab} . / \mathrm{km}^{2}$ (IBGE, 2010). Por sua vez, esse contingente pode revelar a pressão que esta pode causar no ambiente, na medida em que altera a paisagem para extrair os recursos de que necessitam e construírem os objetos. De modo que o valor do Produto Interno Bruto (PIB) desses municípios, por setor da economia, mostra que entre os setores mais pujantes, a agropecuária - que é uma das atividades mais antigas e depreciativa do semiárido - é a segunda que mais contribui, ficando atrás apenas do setor de serviços (Tabela 3). 
Tabela 3 - População e principais setores da economia constituintes do PIB dos municípios da SBHRF.

\begin{tabular}{ccccc}
\hline \multirow{2}{*}{ MUNICÍPIOS } & \multirow{2}{*}{ POPULAÇÃO } & \multicolumn{3}{c}{ ATIVIDADES ECONÔMICAS } \\
& & Agropecuária & Indústria & Serviços \\
\hline Pereiro & 15.757 & $5,20 \%$ & $2,15 \%$ & $86,54 \%$ \\
Ereré & 6.840 & $18,38 \%$ & $3,21 \%$ & $75,5 \%$ \\
Iracema & 13.722 & $13,61 \%$ & $1,66 \%$ & $83,36 \%$ \\
Alto Santo & 16.359 & $24,32 \%$ & $3,92 \%$ & $66,31 \%$ \\
Potiretama & 6.126 & $20,29 \%$ & $2,60 \%$ & $72,76 \%$ \\
\hline
\end{tabular}

Fonte: IBGE (2010; 2017).

A dinâmica geoambiental da sub-bacia não difere da realidade do semiárido brasileiro, pois repercute no contexto físico e natural, bem como no modo de vida dos habitantes, esta fatalidade. Entretanto, é possível tecer especificidades. Em relação as condições climáticas, o quadro pluviométrico das chuvas acumuladas anualmente na série histórica de 1990 a 2020, nos sistemas ambientais da sub-bacia (Figura 3) revela um índice pluviométrico considerável, se comparado a média da região, havendo anos em que chove nessas terras mais de 1500 mm/ano.

O maciço do Pereiro, onde está inserido o município de Pereiro, no extremo sudoeste da subbacia corresponde a $19,5 \%$ da área, sendo uma das serras secas do estado, caracterizada por um relevo dissecado com topografias de fortes declives e altitude que varia entre 500 e $800 \mathrm{~m}$. Essa rugosidade é sustentada por um embasamento cristalino e coberta por vegetação caatinga subperenifólia, no qual os usos da terra se dão por técnicas rudimentares, típicas do nordeste rural, como a agricultura e uma incipiente pecuária, limitadas pelo relevo declivoso da serra (SOUSA, 2012, p. 84).

$\mathrm{Na}$ depressão sertaneja, não há uma homogeneidade paisagística, em que pese os geofácies dos sistemas sertanejos que se apresentam com uma certa diferença física, natural e alterações humanas. Por isso, nos sertões de Pereiro/Ereré, Iracema/Potiretama e Alto Santo, as associações de solo se distinguem exibindo locais com intensa exposição rochosa e solo pedregoso, com uma cobertura vegetal variada, com fortes traços de degradação, conforme evidenciado em campo. As principais reservas hídricas são a barragem do Figueiredo, que adentra ao sertão de Potiretama, e o açude Riacho da Serra, que juntos represam 540.000.000 de $\mathrm{m}^{3}$ (SOUSA, 2012, p. 99).

A supressão da vegetação é o uso mais significativo para sua utilização na atividade ceramista, que é muito forte no município de Alto Santo, constituída por caatinga aberta significativamente degradada, conformando uma paisagem em que se mostram marcas de erosão laminar e em sulco que removeram a camada superficial do solo deixando a rocha exposta. Como visto em campo (Figura 2), o solo é bastante pedregoso sustentando espécies xerófilas como a macambira (Bromélia laciniosa), jurema (Acácia jurema), xique-xique (Pilosocereus polygonus), sabiá (Mimosa caesalpiniaefolia), marmeleiro (Cydonia oblonga) e jucá (Libidibia férrea). 

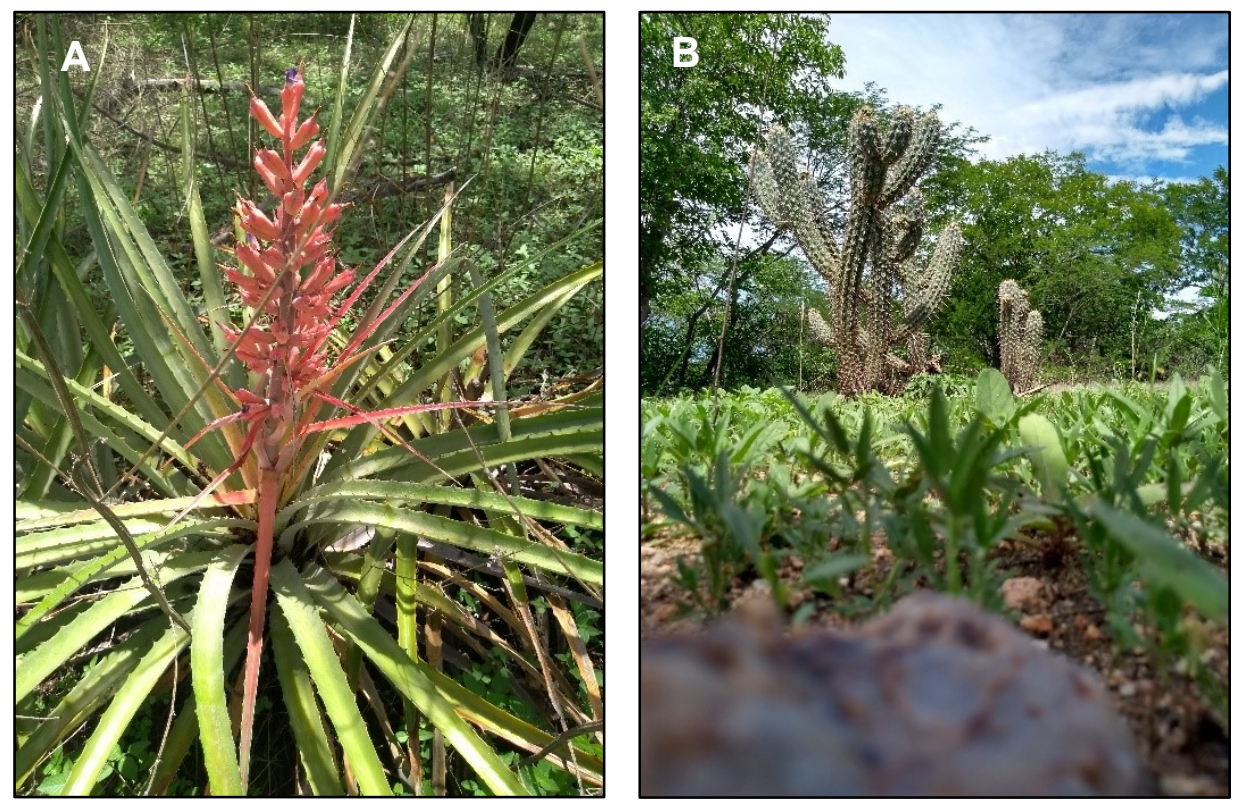

Figura 2 - Espécies vegetais reconhecidas em campo nos sertões de Alto Santo. A - xique-xique (Pilosocereus polygonus) com solo pedregoso; B - macambira (Bromélia laciniosa)

Fonte: Arquivo de Campo (2020). 


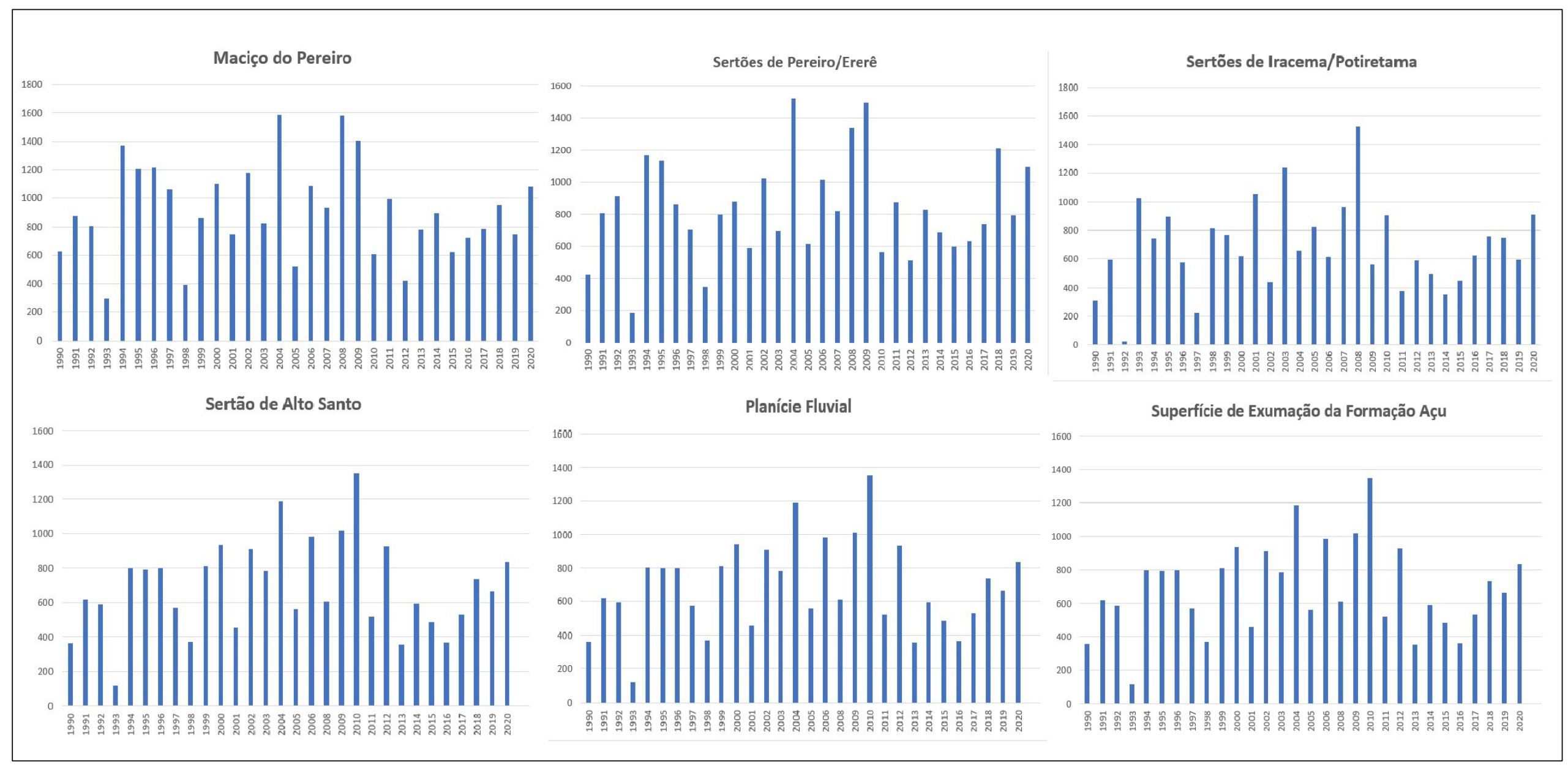

Figura 3 - Gráficos das chuvas acumuladas na série história de 1990-2020 nos sistemas ambientais da SBHRF.

Fonte: Elaboração dos autores, com base em FUNCEME (2020). 
Na planície, a vegetação ciliar se apresenta degradada, pois as áreas têm servido para o desenvolvimento de agricultura cíclica e plantação de capim nas várzeas quando a inundação diminui, remanescendo muito pouca vegetação natural com espécies de carnaúba (Copernicia cerifera). Como também o uso mineral dos Neossolos Flúvicos para as olarias e construção civil (SOUSA, 2012, p. 92).

No extremo nordeste da sub-bacia está a superfície de exumação da Formação Açu que compreende a chapada do Apodi onde se dá o desenvolvimento da agricultura permanente com espécies de cajueiro. Deste uso decorre a forte supressão da caatinga aberta degradada que remanesce na chapada. Conforme visto em campo, a agricultura é em parte mecanizada, na qual além do cajueiro (Anacardium occidentale), plantam-se extensas áreas de feijão, de modo que a paisagem se apresenta como um celeiro agrícola face às limitações aparentes dos sertões.

Por essas características, a sub-bacia exibe fisionomias da paisagem (Figura 4) que indicam a possibilidade da ocorrência do processo de degradação ambiental grave, que pode culminar na desertificação. Nos sertões (Figura 4 B, C, D), em virtude da supressão da vegetação, a suscetibilidade à erosão já se manifesta em sulcos que deixam expostos a rocha matriz em superfície. Na planície (Figura 4 F), a degradação se mostra de maneira significativa no antropismo que devasta a vegetação ciliar. Sendo que esse traço se acentua nas áreas planas e agrícolas da formação Açu (Figura E).

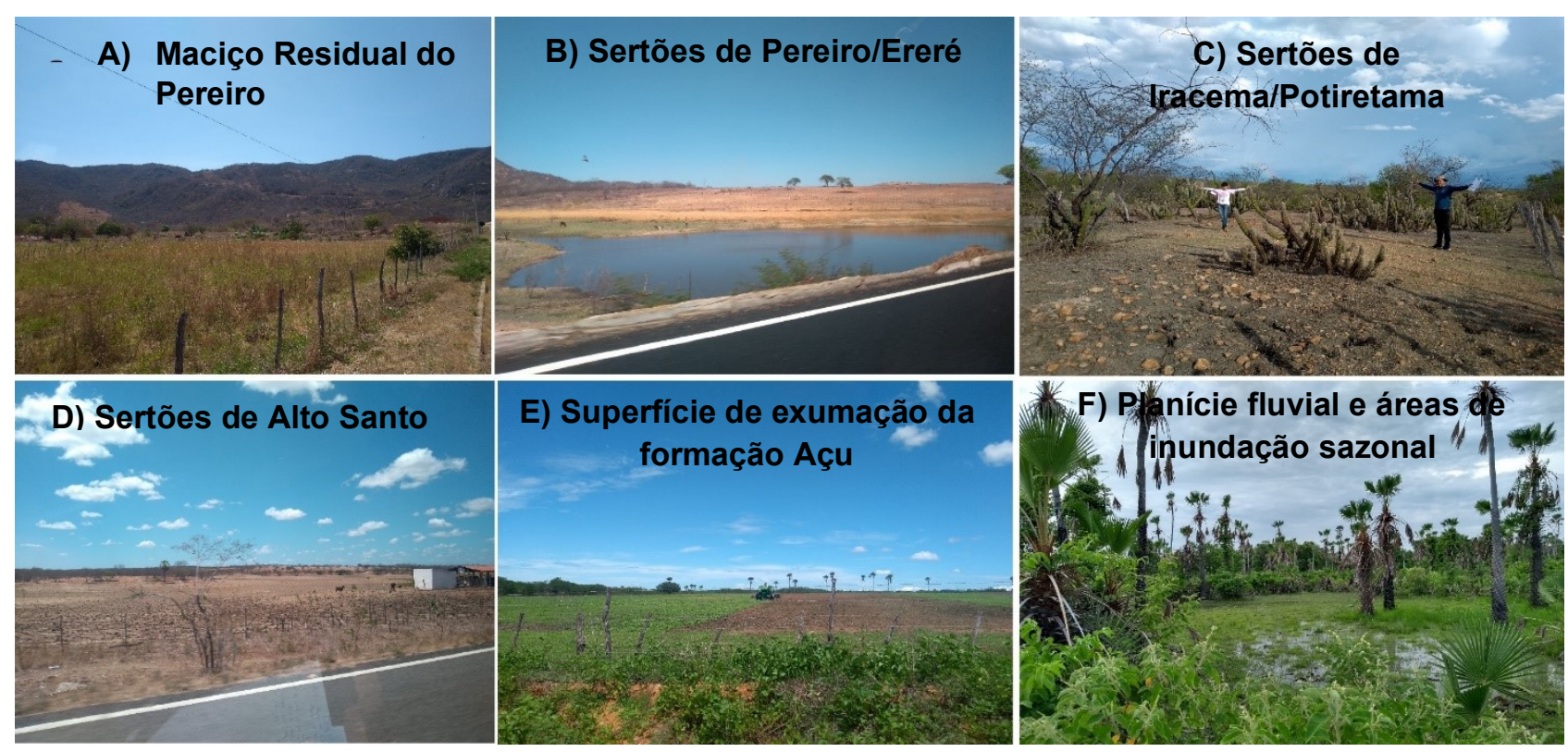

Figura 4 - Mosaico Paisagístico dos sistemas ambientais da SBHRF.

Fonte: Arquivo de campo (2019/2020). 


\section{INDICADORES GEOBIOFÍSICOS DE DESERTIFICAÇÃO NA SBHRF}

\subsection{O Indicador de Geologia}

A identificação da suscetibilidade ao processo de desertificação a partir do indicador de geologia, confere conhecer a litologia da área, grau de porosidade e permeabilidade das rochas dominantes. O embasamento geológico da sub-bacia é predominantemente cristalino, entretanto, há a ocorrência de capeamentos sedimentares, bem como tipos de rochas com variação mineralógica e idades diferentes, ao longo da sub-bacia (Figura 6). Conforme, Cavalcanti e Cavalcante (2014, p. 21) essas rochas são oriundas de episódios ocorridos nos eóns Paleoproterozóico e Neoproterozoico, das eras Mesozoica e Cenozoica, ambos remontando há mais de 2,5 milhões de anos.

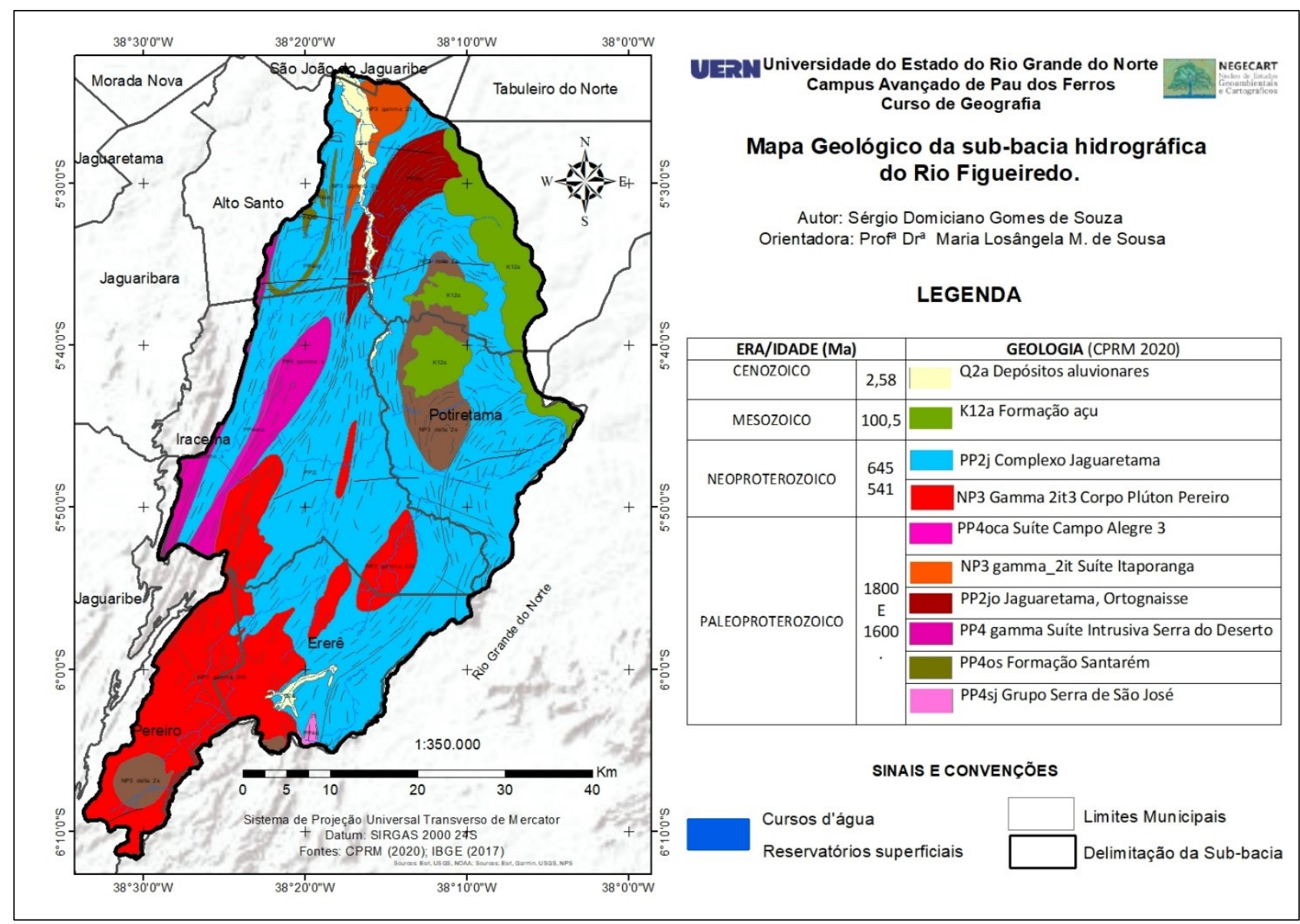

Figura 6 - Mapa Geológico da Sub-bacia Hidrográfica do Rio Figueiredo.

Fonte: Elaboração dos autores (2020).

Nos três sertões, há uma predominância de rochas do complexo nordestino e do complexo Jaguaretama com uma pequena presença de dioritos à Nordeste da sub-bacia (RADAM-BRASIL, 1981; CPRM, 2020). Aqui encontram-se rochas do paleoproterozóico e migmatizadas do magmatismo neoproterozoico como gnaisses do domínio Rio Grande do Norte, bem como xistos e rochas calcicilicáticas (CAVALCANTI; CAVALCANTE, 2014, p. 21; CPRM, 2020). Todas essas 
rochas são de formação metamórficas que possuem porosidade baixa e permeabilidade muito baixa, o que leva a concentração subterrânea de água praticamente nula, com baixa vazão em pontos fraturados (PRESS et. al. 2006, p. 321; MANOEL FILHO, 2008, p. 66).

No sistema do maciço do Pereiro, a permoporosidade também é muito baixa, uma vez que coexistem uma combinação de granitos da suíte magmática ou Suíte intrusiva Itaporanga com xistos, filitos e gnaisses do grupo Ceará, datados do pré-cambriano superior (RADAM-BRASIL, 1981; CPRM, 2020). Por serem ígneas, a porosidade chega a ser quase nula, e seus vazios intercristalinos, que condicionam a porosidade, são mínimos com condutividade hidrogeológica mínima (MANOEL FILHO, 2008, p. 66).

Por sua vez, a planície fluvial constituída de diabásicos toleíticos compostos por sedimentos quaternários de areias finas a grosseiras se apresentam com a melhor permoporosidade dentro da subbacia (RADAM-BRASIL, 1981). Os depósitos cenozoicos aluvionares, estão associados ao leito do rio e riachos, e a grande composição arenosa, pouco consolidada, em virtude da compactação e cimentação mínima entre os grãos de areia (MANOEL FILHO 2008, p. 64; CAVALCANTI; CAVALCANTE, 2014, p. 31; CPRM, 2020).

Já na área da superfície de exumação da Formação Açu, na chapada do Apodi, datada da Era mesozoica, especialmente do Cretáceo com aproximadamente $100 \mathrm{Ma}$, a constituição de arenitos sobrepostas ao manto cristalino, logra a esta superfície porosidade e permeabilidade não muito boa, em virtude da composição de argila entre os grãos de areia. Mesmo assim, é uma área de condutividade hidrogeológica superior a rusticidade geológica da depressão e do maciço residual (POMPEU SOBRINHO, 1941, p. 160; CPRM, 2020).

\subsection{O Indicador de Solos}

Os solos, como um elemento natural da superfície terreste, é produto da interação dos demais componentes geoambientais, pois é oriundo diretamente da decomposição das rochas e matéria orgânica sob a força intempérica do clima, quer seja o calor do sol ou a água das chuvas, se formando espacialmente diferente conforme as condições do ambiente.

No tocante as associações de solos presentes na sub-bacia, estes são heterogêneos, embora haja uma grande mancha de Argissolos Vermelhos-Amarelos do extremo Sul em direção a porção central da área, e outra grande mancha de Neossolo Litólico da porção central ao extremo Norte do território (Figura 7). 


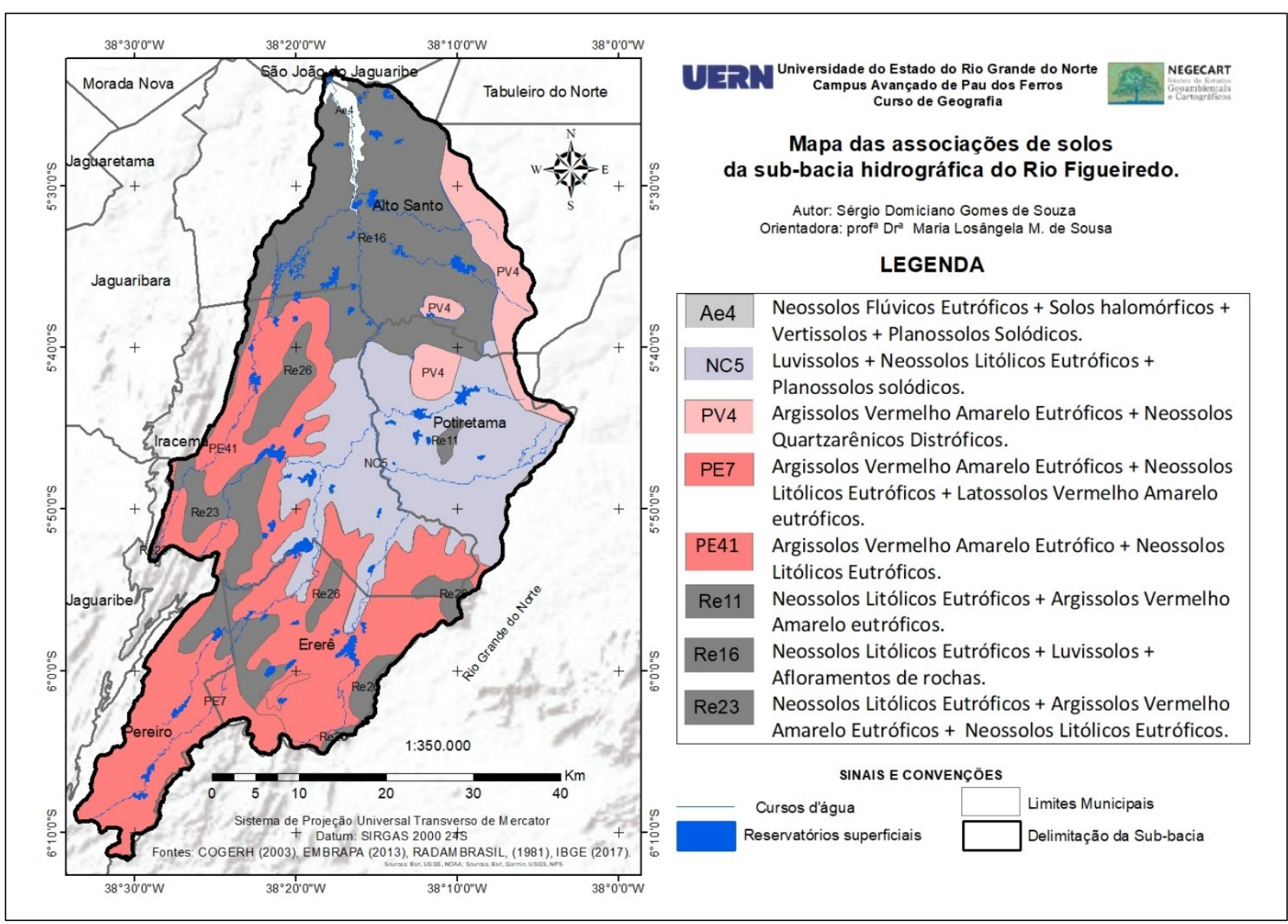

Figura 7- Mapa das associações de solos da SBHRF.

Fonte: Elaboração dos autores (2020).

No maciço residual do Pereiro, há solos do tipo Argissolos Vermelho-Amarelo com Latossolos Vermelho-Amarelo em grande parte da área com associações de Neossolos Litólicos encravados, formados em rochas graníticas de textura fina a grosseira e dispostos em feições do relevo com formas convexas a aguçadas separadas por vales em $\mathrm{V}$, com declividades que atingem a ordem dos 50\% podendo levar a movimentos de massa (RADAM-BRASIL, 1981). Assim estes solos, por serem bem desenvolvidos e cobertos por uma vegetação caatinga arbórea densa com intercalações de cultura cíclica, regadas por uma intensidade pluviométrica de 187,4 mm/ano (FUNCEME, 2019), concentrados em quatro meses, dispõe este geoambiente à vulnerabilidade à erosão medianamente estável/vulnerável.

Nos sertões de Pereiro/Ereré, com cotas morfométricas menores, a dissecação apresenta feições tabulares separadas por vales de fundo plano, e formas aguçadas com vales em $\mathrm{V}$ em áreas próximas as elevações do maciço e das cristas residuais que aparecem no meio da depressão (RADAM-BRASIL, 1981). Nesse geoambiente embasado por rochas magmáticas com gnaisses variados (CPRM, 2020), os solos que o cobrem e suportam uma vegetação de caatinga densa e aberta degradada com culturas cíclicas, são de bom desenvolvimento ainda que apareçam Luvissolos e Neossolos Litólicos associados a presença de Argissolos e Latossolos. Somados a 
esses atributos, a intensidade pluviométrica de 385,6 mm/ano (FUNCEME, 2019) concentrada em quatro meses nesses sertões de muito baixa declividade, conferem uma vulnerabilidade moderadamente estável (Figura 6).

Já nos sertões de Iracema/Potiretama, a disposição à perda de solo é um pouco mais acentuada em relação aos sertões de Pereiro/Ereré, com um grau moderadamente estável. Isso se dá pela rugosidade do relevo, que apresenta dissecação com formas variadas de convexas a aguçadas separadas por vale em $\mathrm{V}$ e algumas feições com formas tabulares e vale de fundo plano (RADAMBRASIL, 1981). Estas estão embasadas em rochas de baixa denudação compostas por migmatitos e gnaisses variados, sobrepostos por Luvissolos e Neossolos Litólicos, de maturidade intermediária, cobertos por uma vegetação de caatinga aberta em sua maioria. Ainda, a intensidade pluviométrica concentrada nos quatros primeiros meses do ano de $160 \mathrm{~mm} / \mathrm{ano}$ (FUNCEME, 2019).

Na terceira porção da depressão sertaneja, os sertões de Alto Santo, as rochas são gnaisses migmatitos, xistos e filitos de baixa denudação que comportam um relevo com formas convexas, aguçadas e até tabulares com declividade aplainada (RADAM-BRASIL, 1981). Os solos são do tipo Neossolos Litólicos, Luvissolos e Argissolos, cobertos por caatinga aberta que oferece pouca proteção a intensidade pluviométrica de $458,2 \mathrm{~mm}$ /ano nos três primeiros meses do ano, o que dispõe esse ambiente a perda de solo medianamente estável com tendência á vulnerável (FUNCEME, 2019).

Contrastando o maciço e os sertões, a superfície de exumação da formação Açu, possui uma alta denudação das rochas, constituídas por arenitos que formam um relevo predominantemente tabular com vales de fundo plano, amplitude altimétrica muito fraca e declividade muito baixa (RADAM-BRASIL, 1981). Essas rochas e feições estão sobrepostos por Argissolos VermelhoAmarelo associados a Neossolos Quartzarênicos expostos pela baixa cobertura de caatinga aberta degradada em meio às áreas de agricultura onde precipitam em média 374,1 mm/ano nos quatro primeiros meses do ano (FUNCEME, 2019). Como consequência, este geoambiente é medianamente estável/vulnerável a perda de solo.

A planície fluvial do Rio Figueiredo é constituída por rochas com alto grau de denudação, como as areias finas a grosseiras dos sedimentos inconsolidados do Quaternário (RADAM-BRASIL, 1981; CPRM, 2020). Este embasamento, conforma uma feição plana onde se desenvolvem Neossolos Flúvicos, Vertissolos e Planossolos com suas margens cobertas por mata ciliar fortemente degradada e presença de caatinga e carnaúbas. Nessas áreas a intensidade pluviométrica é de 186,7 mm/ano (FUNCEME, 2019) que predispõe a uma taxa de perda de solo por erosão hídrica medianamente estável tendendo a vulnerável.

Assim, as condições geoambientais desses sistemas levam a uma vulnerabilidade a erosão variável em função das condições de cada sistema (Figura 8). De modo que a área de maior suscetibilidade a esse fenômeno é o maciço residual do Pereiro, os sertões de Alto Santo, a Planície 
Fluvial e a superfície da formação Açu, onde aparecem sulcos abertos com rocha matriz exposta, conforme comprovados em campo.

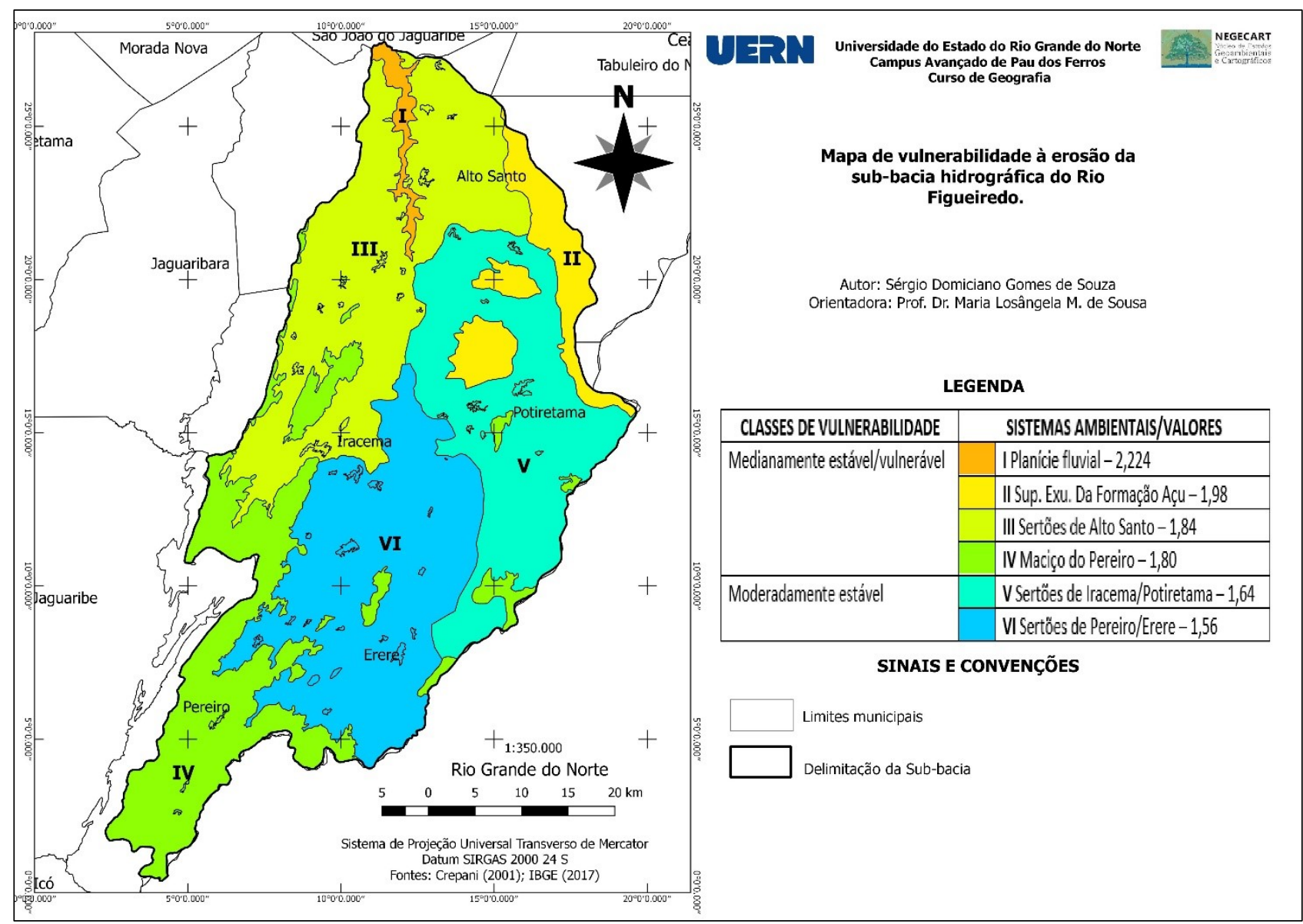

Figura 8 - Mapa de vulnerabilidade à erosão na SBHRF.

Fonte: Elaboração dos autores (2020).

\subsection{O Indicador de Vegetação}

O padrão original da vegetação da sub-bacia está condicionado às intempéries causadas pela ocupação humana. Este fato deve-se ao povoamento dessas áreas que remontam ao estabelecimento de atividades agrícolas e a pecuária, demandando a supressão da vegetação primária no contexto de ocupação territorial do Ceará, em que as áreas banhadas pelo Rio Jaguaribe foram povoadas por sesmeiros (SOUSA; OLIVEIRA, 2018, p. 263).

O mapa de uso e cobertura da terra (Figura 9) demonstra não somente as tipologias dos usos, mas o estado atual da vegetação, resultado da ocupação histórica que se apresenta bastante variegado e antropizado em toda a extensão. 


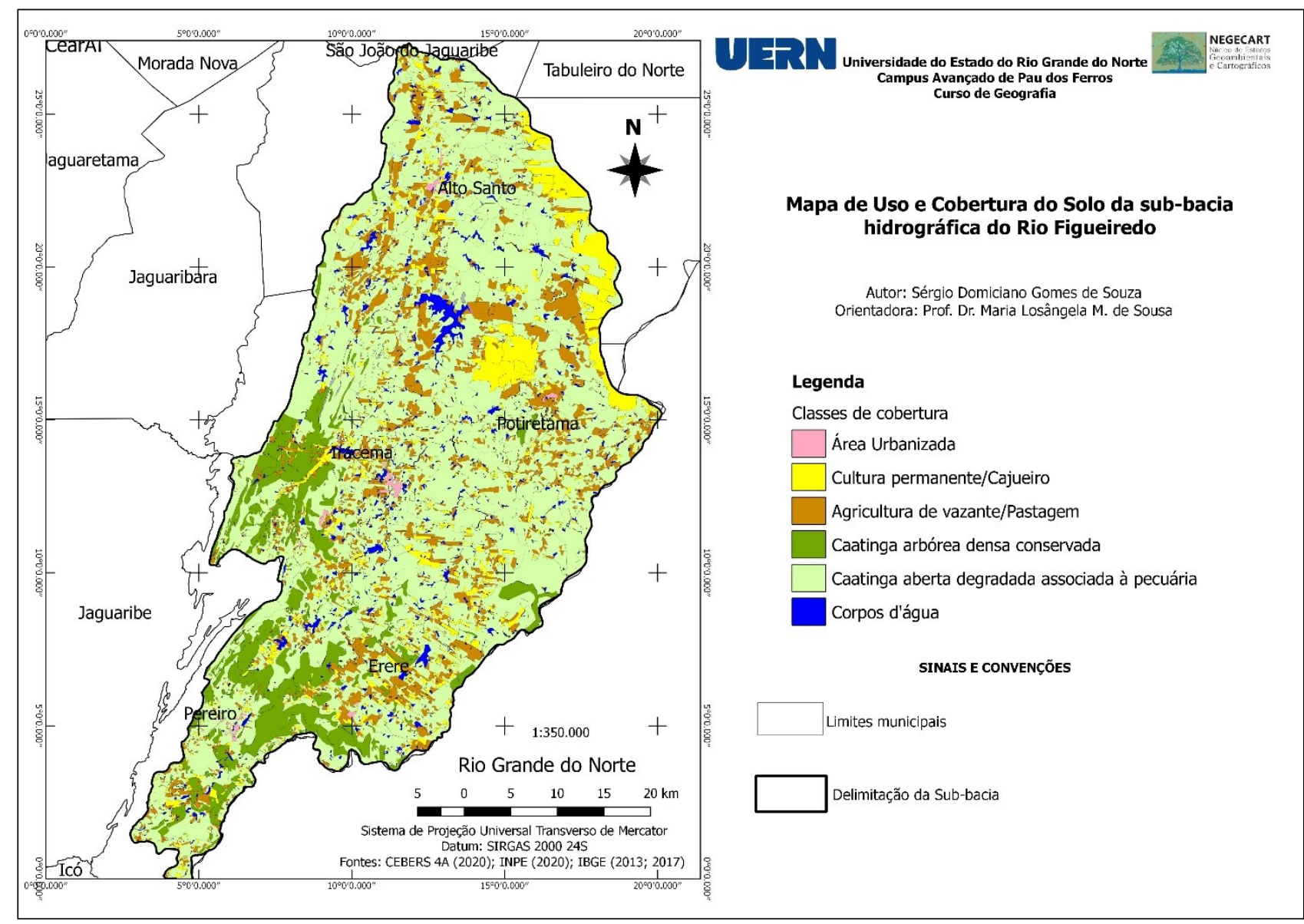

Figura 9 - Mapa de uso e cobertura do solo da SBHRF. Fonte: Elaboração dos autores (2020).

No maciço tem-se a cobertura vegetal em melhores condições, pois apesar de ser um ambiente de serra seca, trata-se da área de maior altitude, e, portanto, uma declividade mais acentuada o que dificulta o desenvolvimento da agropecuária em relação aos outros geoambientes. Por isso, a vegetação de caatinga arbórea densa cobre $35 \%$ das encostas.

Nos três sertões, a cobertura vegetal apresenta um nível de antropização maior, pois somente em Pereiro/Ereré e Iracema/Potiretama, nas imediações onde se situam as cristas residuais, remanesce uma caatinga arbórea densa com padrão conservado, fronteiriça a uma extensão de caatinga aberta degradada pela pastagem, agricultura e extrativismo vegetal indiscriminado. Por outro lado, em Alto Santo, predomina a cobertura de caatinga arbórea aberta com significativas áreas de agricultura de vazante e pastagem. Nos três sistemas ambientais, a cobertura vegetal é baixa, deixando os solos expostos aos efeitos erosivos das chuvas torrenciais, uma vez que os usos ligados a pastagem, agricultura e cobertura de caatinga aberta fortemente degradada somam cerca de $90 \%$ dos sertões.

Na planície fluvial do Rio Figueiredo, a cobertura vegetal também é baixa, constituída predominantemente por caatinga aberta degradada ao longo da faixa ripária, com áreas de pastagem e agricultura de vazante no período em que não está inundada. Este domínio, junto a superfície de exumação da Formação Açu, representam as unidades com menor cobertura vegetal, pois não 
remanescem caatinga de porte denso, uma vez que só na chapada, $60,76 \%$ é coberta por cultura permanente/cajueiro. Por essa razão, em toda a sub-bacia, essa superfície configura-se como sendo o celeiro da produção agrícola.

Desse modo, considerando os atributos que estruturam os indicadores de geologia, solos e vegetação, os valores estabelecidos para cada um se organizam como demonstra a tabela 4. A partir dos quais gerou-se o panorama da suscetibilidade dos sistemas ambientais da sub-bacia hidrográfica do Rio Figueiredo, conforme a tabela 5.

Tabela 4: Índices de susceptibilidade à desertificação dos sistemas ambientais da SBHRF.

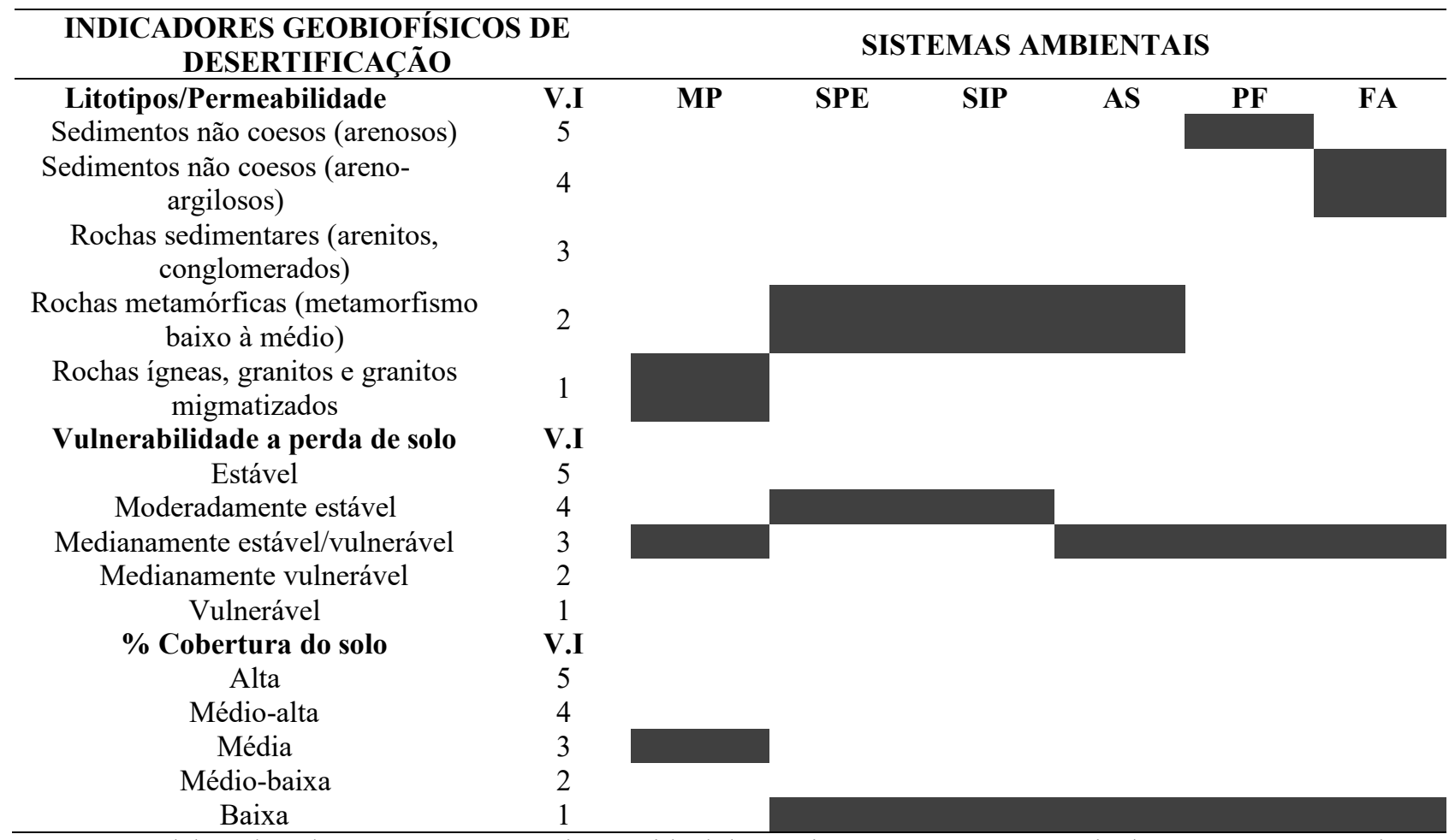

Fonte: Elaborado pelos autores. MP: Maciço Residual do Pereiro; SPE: Sertões e Pereiro/Ereré; SIP: Sertões de Iracema/Potiretama; SA: Sertão de Alto Santo; PF: Planície Fluvial; FA:Superfície de exumação da formação Açu.

Tabela 5: Suscetibilidade à Desertificação dos sistemas ambientais da SBHRF.

\begin{tabular}{ccc}
\hline SISTEMA AMBIENTAL & IGBFD & $\begin{array}{c}\text { SUSCEPTIBILIDADE Á } \\
\text { DESERTIFICAÇÃO }\end{array}$ \\
\hline Maciço Residual do Pereiro & 2,33 & Alto \\
Sertões e Pereiro/Ereré & 2,33 & Alto \\
Sertão de Alto Santo & 2,33 & Alto \\
Sertões de Iracema/Potiretama & 2 & Alto \\
Planície Fluvial & 3 & Moderado \\
Superfície de exumação da formação açu & 2,66 & Alto \\
\hline
\end{tabular}

Fonte: Elaborados pelos autores. 
O indicador de geologia, dado pelo grau de permeabilidade das rochas, demonstra que por esta ser baixa no Maciço do Pereiro e nos Sertões, são nessas áreas onde a suscetibilidade a desertificação é maior em que pese a baixa condutividade hidráulica e espaços porosos do embasamento granítico.

Já a vulnerabilidade dos sistemas ambientais à erosão, a suscetibilidade desses a desertificação é mediana, pois apresentam classes variando entre medianamente estável com tendência a vulnerável, dada pelos atributos geoambientais em sua perspectiva sistêmica.

Para o indicador de vegetação, por apresentar um mosaico paisagístico marcado pelos usos, é no maciço em que se encontra a melhor cobertura, ainda que seja quantitativamente média, contrastando a cobertura das outras unidades, pois por serem cobertos por caatinga aberta degradada, a qualidade dessa cobertura é baixa podendo repercutir na incapacidade de proteção dos solos e nos processos morfodinâmicos.

\section{CONSIDERAÇÕES FINAIS}

Tendo em vista os aspectos analisados, no tocante ao potencial ecológico, a exploração biológica e a ação humana que conformam os sistemas ambientais da Sub-bacia Hidrográfica do Rio Figueiredo, esta se apresenta predisposta à ocorrência da desertificação, mesmo com a baixa densidade demográfica que já repercutem negativamente nos sistemas ambientais, como a supressão da cobertura vegetal e processos de erosão.

Dessa forma, pelos indicadores aplicados, verifica-se de forma singular, que a geologia da área marcada pela baixa permoporosidade das rochas, influencia decisivamente na limitação de água subterrânea. Os solos, estão vulneráveis aos processos erosivos, sobretudo pela cobertura vegetal fortemente degradada que não oferece proteção das chuvas torrenciais, e por outros condicionantes geoambientais, como a alta denudação das rochas - na Formação Açu e na Planície Fluvial, por serem arenosas são mais susceptíveis a erosão.

Portanto, a metodologia dos indicadores geobiofísicos é válida, pois a pesquisa ora executada atingiu seus objetivos, demonstrando que não havendo uma gestão ambiental adequada capaz de orientar os usos e estabelecer medidas mitigadoras, a vulnerabilidade que hoje é alta, poderá trazer consequências graves ao ambiente e à população da SBHRF.

Resta, doravante, com os resultados adquiridos até então, avançar em uma agenda de pesquisa que considere o holismo necessário a elucidação da desertificação na sub-bacia, dando atenção a outros indicadores que congreguem este quadro natural ao social e institucional no que tange ao ordenamento do território voltado às adversidades socioambientais do semiárido brasileiro. 


\section{REFERÊNCIAS}

ABRAHAM, E. M.; BEEKMAN, G. B. Indicadores de la Desertificación para América del Sur. Editorial Martín Fierro. Mendonza: 2006, 374p.

ARAUJO, G. H. S.; ALMEIDA, J. R.; GUERRA, A. J. T. Gestão Ambiental de Áreas Degradadas. Rio de Janeiro: Bertrand Brasil, 2010. 320p.

BERTRAND, G. Paisagem e Geografia Física Global: esboço metodológico. Tradução: Olga Cruz. R. RA'E GA, Curitiba, n. 8, p. 141-152, 2004

BRASIL. Instituto Brasileiro de Geografia e Estatística. IBGE Cidades. 2010. Disponível em: https://cidades.ibge.gov.br/. Acesso em: 01 out. 2020.

BRASIL. Instituto Brasileiro de Geografia e Estatística. Produto Interno Bruto dos Municípios. 2017. Disponível em: https://www.ibge.gov.br/estatisticas/economicas/contas-nacionais/9088produto-interno-bruto- $\mathrm{d}$ os-municipios.html? $=\& \mathrm{t}=\mathrm{o}$-que-e. Acesso em: 01 out. 2020.

BRASIL. Ministério do Meio Ambiente. Programa de Ação Nacional de Combate à Desertificação e Mitigação dos Efeitos da Seca (PAN-BRASIL). Brasília: Edições MMA, 2004, $213 p$.

BRASIL. Ministério de Minas e Energia. Projeto RADAMBRASIL. Folha SB.24/25 Jaguaribe/Natal. Rio de Janeiro, 1981. (Levantamento de recursos naturais).

CAVAlCANTI, J. A D.; CAVAlCANTE, J. C. Evolução geológica. In: BRANDÃO, R. L.; FREITAS, L. C. (Org.) Geodiversidade do estado do Ceará. Fortaleza: CPRM, 2014, p. 21-31.

CEARÁ. Secretaria dos Recursos Hídricos. Programa de Ação Estadual de Combate à Desertificação e Mitigação dos Efeitos da Seca (PAE-CE). Fortaleza, 2010. 374p.

CEARÁ. Fundação Cearense de Meteorologia e Recursos Hídricos (FUNCEME). Calendário de chuvas do estado do Ceará. 2019. Disponível em: http://www.hidro.ce.gov.br/hidro-cezend/app/pagina/show/186. Acesso em: 15 out. 2020.

CONTI, J. B. O conceito de desertificação. Climatologia e estudos da paisagem, Rio Claro, v. 3 , n. 2, p. 93-52, 2008.

CPRM. Ministério de Minas e Energia. Serviço Geológico do Brasil. Mapa Geológico do Estado do Ceará. 2020.

CREPANI, E.; MEDEIROS, J. S.; FILHO, P. H.; FLORENZANO, T. G.; DUARTE, V.; BARBOSA, C. C. F. Sensoriamento remoto e geoprocessamento aplicados ao zoneamento ecológicoeconômico e ao ordenamento territorial. São José dos Campos: INPE, 2001, 124p. Disponível em: http://sap.ccst.inpe.br/artigos/CrepaneEtAl.pdf. Acesso em: 03 set. 2020.

MANOEL FILHO, J. A. Ocorrência de águas subterrâneas. In: FEITOSA, F. A. C. Hidrogeologia: conceitos e aplicações. $3^{\circ}$ ed. Rio de Janeiro: CPRM, LABHID, 2008, p. 53-74.

NASCIMENTO, F. R. O fenômeno da desertificação. Goiânia: Ed. UGG, 2013. 244p. 
OLIVEIRA, V. P. V. Indicadores Biofísicos de Desertificação, Cabo Verde/África. Mercator, Fortaleza, v. 10, n. 22, p. 147-168, 2011.

POMPEU SOBRINHO, T. P. Estrutura geológica do Ceará: noções estratigráficas e geogenia. Revista do Instituto do Ceará, Fortaleza, n. 55, p. 159-175, 1941.

PRESS, F.; SIEVER, R.; GROTZINGER, J.; JORDAN, T. H. Para entender a terra. 4. ed. Porto Alegre: Bookman, 2006, 656p.

PRODANOV, C. C.; FREITAS, E. C. Método Científico. In: Metodologia do trabalho científico [recurso eletrônico]: Métodos e técnicas da pesquisa e do trabalho acadêmico. 2 ed. Novo Hamburgo: Feevale, 2013, p. 24-39. Disponível em: https://www.feevale.br/institucional/editorafeevale/metodologia-do-trabalho-cientifico---2-edicao. Acesso em: 03 set. 2020.

SANTOS, H. G.; JACOMINE, P. K. T.; ANJOS, L. H. C.; OLIVEIRA, V. A.; LUMBRERAS, J. F.; COELHO, M. R.; ALMEIDA, J. A.; ARAÚJO FILHO, J. C.; OLIVEIRA, J. B.; CUNHA, T. J. F. Sistema brasileiro de classificação dos solos. EMBRAPA solos - Livro Técnico. $5^{\circ}$ ed. rev. e ampl. 2018. 355p.

SOTCHAVA, V. B. O estudo de Geossitemas. Métodos em Questão. Universidade de São Paulo Instituto de Geografia: São Paulo, 1977, 50p.

SOUSA, M. L. M. Susceptibilidade à Degradação/Desertificação na Sub-Bacia Hidrográfica do Riacho Feiticeiro (Ceará/Brasil) e na Microbacia da Ribeira Grande (Santiago/Cabo Verde). 2016. 215 f. Tese (Doutorado em Geografia). Universidade Federal do Ceará, Fortaleza, 2016.

SOUSA, M. L. M. Diagnóstico Geoambiental da Sub-Bacia Hidrográfica do Rio Figueiredo, Ceará: Subsídios ao Planejamento Ambiental. 2012. 144 f. Dissertação (Mestrado em Geografia). Universidade Federal do Ceará, Fortaleza, 2012.

SOUSA, M. L. M. de; OLIVEIRA, V. P. V. de. Histórico de uso e ocupação da terra e condições socioeconômicas da sub-bacia hidrográfica do Rio Figueiredo - Ceará. In: SOUSA, M. L. M.; OLIVEIRA, V. P. V. (Orgs). A Geografia aplicada ao semiárido brasileiro: desafios e perspectivas. Fortaleza: Expressão Gráfica e Editora, 2018. p. 257-277.

SOUZA, S. D. G.; SOUZA, A. C. N.; SOUSA, M. L. M. Clima, recursos hídricos, solos e vegetação como indicadores geobiofísicos de desertificação no alto//médio curso da bacia hidrográfica do rio Apodi/Mossoró-RN. In: DELFINO, L. D.; SOUSA, M. L. M.; SILVA, J. B. (Orgs). Sustentabilidade, políticas públicas e interdisciplinaridade no semiárido. Pau dos Ferros: RedeTER, v. 3, 2020. p. 244-257.

TRICART, J. Ecodinâmica, Rio de Janeiro: IBGE/SUPREN, 1977, 97p.

VEADO, R. A. O Geossistema: Embasamento Teórico e Metodológico (Relatório de qualificação). UNESP: Rio Claro, 1995. 